\begin{tabular}{|c|l|}
\hline Title & The water relation of seedlings of Piceajezoensis on fallen logs \\
\hline Author(s) & Iijima, Hay ato; Shibuya, Masato; Saito, Hideyuki; Takahashi, Kunihide \\
\hline Citation & $\begin{array}{l}\text { Canadian journal of forest research, 36(3), 664-670 } \\
\text { https://doi.org/10.1139/X 05.285 }\end{array}$ \\
\hline Issue Date & 2006-03 \\
\hline Doc URL & http://hdl.handle.net/2115/12203 \\
\hline Rights & (c)2006 NRC Canada \\
\hline Type & article (author version) \\
\hline File Information & IijimaHayato.pdf \\
\hline
\end{tabular}

Instructions for use 


\title{
Water relation of Picea jezoensis seedlings on fallen $\operatorname{logs}$
}

\author{
Hayato Iijima ${ }^{1)} \quad$ Masato Shibuya $^{1)} \quad$ Hideyuki Saito ${ }^{1)}$ \\ Kunihide Takahashi1 ${ }^{1)}$
}

Affiliation and address:

1) Graduate School of Agriculture, Hokkaido University, Sapporo 060-8589, Japan

Hayato Iijima: hayato-i@for.agr.hokudai.ac.jp

Masato Shibuya: shibuya@for.agr.hokudai.ac.jp

Hideyuki Saito: saito@for.agr.hokudai.ac.jp

Kunihide Takahashi: kun23@for.agr.hokudai.ac.jp

Corresponding Author:

Name: Hayato Iijima

Address: Graduate School of Agriculture, Hokkaido University, Sapporo 0608589, Japan

Telephone number: +81-11-706-3346

Fax number: +81-11-706-3346

E-mail address: hayato-i@for.agr.hokudai.ac.jp 


\begin{abstract}
We examined whether fallen logs without mosses $\left(\mathrm{FL}_{B}\right)$ are more droughtstressful sites in forests for Picea jezoensis Carr. seedlings than are logs with mosses $\left(\mathrm{FL}_{M}\right)$, and whether drought affects the mortality of seedlings on logs. We measured the water potential of log humus layer $\left(\Psi_{H}\right)$ and needles of seedlings on the $\operatorname{logs}\left(\Psi_{N}\right)$ in a natural forest and a greenhouse under various drought conditions. We also determined the critical $\Psi_{N}$ from the relationship between seedlings mortality, $\Psi_{N}$ and chlorophyll fluorescence $(\mathrm{Fv} / \mathrm{Fm})$. The $\Psi_{H}$ on both moss-covered and bare logs in the forest was $0 \mathrm{MPa}$, regardless of the number of days without precipitation. In the forest, the mean predawn $\Psi_{N}$ of $\mathrm{FL}_{B}$ and $\mathrm{FL}_{M}$ measured 11 days after a rainfall was -0.8 and $-0.7 \mathrm{MPa}$, respectively, in the driest season. The $\Psi_{N}$ for $P$. jezoensis seedlings of $\mathrm{FL}_{B}$ reached to critical value earlier than that of $\mathrm{FL}_{M}$ in the greenhouse, but this occurred after a long period ( $>30$ days) with no irrigation. We concluded that drought does not cause mortality of $P$. jezoensis seedlings on fallen logs in natural forests.
\end{abstract}




\section{Introduction}

The regeneration of trees on fallen logs is a common phenomenon in boreal forests (Suzuki et al. 1987; Harmon and Franklin 1989; Taylor 1990; Szewczyk and Szwagrzyk 1996; Mori et al. 2004). Fallen logs function as safe sites for tree seedlings because there is no competition with herbs (Harmon and Franklin 1989; Maruyama et al. 2004), and there are few pathogenic fungi that can infect tree seeds and seedlings (Cheng and Igarashi 1986; 1987; Takahashi 1991). The regeneration of trees is also affected by the physical properties of fallen logs, such as the decay rate. For example, seedling density on recently fallen, moss-free logs is low (McCullough 1948; Takada et al. 1973; Christy and Mack 1984; Simard et al. 1998; Takahashi et al. 2000; Narukawa et al. 2003). However, the causes of the variation in seedling density on logs have not been conclusively established.

Drought stress is one of the causes of low seedling density on recently fallen logs (Takada et al. 1973; Takahashi et al. 2000; Narukawa et al. 2003). The surface water content of logs is affected by the presence of mosses (Takahashi et al. 2000), which grow on the logs as they decay. Takahashi et al. (2000) surveyed Picea jezoensis seedling density in a natural coniferous forest in Hokkaido, northern Japan, in relation to water-soluble nutrients and water content in the stems and humus layer of logs, from which the seedlings absorb water and nutrients (Harmon and Franklin 1989; Nakamura 1992). They showed that seedling density and water content were 
lower on freshly fallen, moss-free logs than on decayed, moss-covered logs. Harmon (1987) surveyed the survival and growth of Picea sitchensis and Tsuga heterophylla seedlings on two types of logs: newly fallen logs to which litter and humus were added on the surface and newly fallen logs that received no treatment. He showed that survival and growth of seedlings were enhanced on logs supplemented with litter and humus. Freshly fallen logs have been suggested to represent xeric sites for seedlings because their hard texture makes it difficult for seedlings to absorb water (Harmon 1987; Takahashi et al. 2000). Conversely, decayed logs with mosses are suggested to represent mesic sites for seedlings because mosses build up the humus layer on the logs and improve the moisture conditions (Harmon 1987; Harmon and Franklin 1989; Takahashi et al. 2000). Furthermore, moss cover reduces the rate of evaporation from logs. However, these previous studies did not intensively examine the drought hypothesis to explain the variation in seedling density on fallen logs with and without mosses. Specifically, they did not continually measure the water status of the logs or the seedlings, and the effect of drought stress on seedling survival was not determined (Harmon 1987; Takahashi et al. 2000).

P. jezoensis regenerates mainly on fallen logs in natural forests (Kubota et al. 1994; Takahashi 1994; Hiura et al. 1996; Nakagawa et al. 2001). To understand the natural regeneration process of $P$. jezoensis, it is necessary to examine the drought hypothesis to explain the variation in seedling density on fallen logs because the initial survival rate of $P$. jezoensis seedlings significantly affects the variability in 
seedling density on fallen logs (Takada et al. 1973). Moreover, seedling mortality during the growing season is assumed to be caused by drought stress (Cheng and Igarashi 1985; Natsume 1985).

The objective of our study was to examine the drought hypothesis to explain the variation in $P$. jezoensis seedling density on fallen logs with and without mosses. In this study, we examined the drought hypothesis as follows. 1) The drying processes of fallen logs with and without mosses were compared in a natural forest and in a temperature-controlled greenhouse. The water status of the logs was measured continually throughout a growing season because it changed with varying levels of precipitation in the natural forest. Water status was also measured in a temperature-controlled greenhouse because night dew occurred frequently in the natural forest. 2) Critical drought stress for seedling survival was determined by measuring the water potential and chlorophyll fluorescence (ratio of variable fluorescence to maximum fluorescence: $\mathrm{Fv} / \mathrm{Fm}$ ) of needles. The needle or leaf water potential indicates the water balance status in a plant (Larcher 1995), but the critical water potential depends on the ontogeny of the seedlings (Donovan and Ehleringer 1991, 1992; Cavender and Bazzaz 2000). The Fv/Fm ratio is stable under dark conditions, even when leaves are highly drought stressed (Genty et al. 1986; Di-Marco et al. 1988; Ann et al. 1995; Lu and Zhang 1998; Augusti et al. 2001). Therefore, it is possible to estimate the degree of critical drought stress in seedlings by measuring the water potential and Fv/Fm ratio of their needles. 3) The length of the 
drought period that caused critical drought stress for seedling survival was estimated by measuring the water potential of needles and logs in the temperature-controlled greenhouse. 4) The possibility of occurrence of critical drought in the natural forest was estimated based on the results of 2) and 3) and a 10-year meteorological data set of hourly precipitation records.

\section{Method}

\section{Study site and plant materials}

We measured the water status of fallen logs and P. jezoensis seedlings growing on the logs several times during a dry period in a coniferous forest in central Hokkaido, northern Japan. We defined the water status of fallen logs as the water potential of the humus layer $\left(\Psi_{H}\right)$, and the water status of seedlings as the water potential of their needles $\left(\Psi_{N}\right)$. Our field study was conducted in Sou-unkyo, Taisetsuzan National Park ( $43^{\circ} 39^{\prime} \mathrm{N}, 143^{\circ} 06^{\prime}$ E; 950m above sea level [a.s.l.]). A permanent plot $(100 \times 200 \mathrm{~m})$ was established by the Hokkaido research center of the Forestry and Forest Products Research Institute (FFPRI), Hitsujigaoka, Sapporo, Japan. The tree density and total basal area (BA) of trees $>5 \mathrm{~cm}$ in diameter at breast height (DBH) in the plot were 642 trees $\mathrm{ha}^{-1}$ and $53.8 \mathrm{~m}^{2} \mathrm{ha}^{-1}$, respectively. Picea glehnii Masters, P. jezoensis Carr., Abies sachalinensis Masters, and broadleaf trees accounted for $43,29,28$, and $0.1 \%$ of the BA, respectively (Table 1 ). The canopy 
height of the stand was 25-30 m. The ground vegetation was dominated by dwarf bamboo (Sasa senanensis Rehd.). The mean annual temperature measured in the plot in 2003 was $4.1^{\circ} \mathrm{C}$. In this stand, the mean vapor pressure deficit of the air (VpdA) was $0.28 \mathrm{kPa}$ during the growing season from May to October 2003, calculated from the air temperature and relative humidity recorded by a thermo-humidity sensor (RS-10, Espec Mic. Co., Aichi, Japan). The mean annual precipitation at the nearest meteorological station in Sou-unkyo $\left(43^{\circ} 45^{\prime} \mathrm{N}, 142^{\circ} 55^{\prime}\right.$ E; $540 \mathrm{~m}$ a.s.l.) was $1399 \mathrm{~mm}$ from 1994-2003, with $1358 \mathrm{~mm}$ in 2002 and $1088 \mathrm{~mm}$ in 2003 (Fig. 1). Meteorological data were obtained from the website of the Japan Meteorological Agency (http://www.data.kishou.go.jp/etrn/). No forestry operations have been conducted in this plot since a strong typhoon occurred in September 1954 (Tamate et al. 1977); thus, many fallen logs were found. For our measurements, we selected four moss-free ("bare") fallen logs with bark $\left(\mathrm{FL}_{B}\right)$ and four moss-covered fallen $\operatorname{logs}\left(\mathrm{FL}_{M}\right)$ in 2002, and 10 each of $\mathrm{FL}_{B}$ and $\mathrm{FL}_{M}$ in 2003. Mosses were the only vegetation on the logs. $\mathrm{FL}_{M}$ were covered mainly with Campylium squarrosulum (Broth. \& Card.) Kanda, and the height of the moss was $9.6 \pm 3.6 \mathrm{~mm}$ (average \pm SD). We selected fallen logs of P. jezoensis, P. glehnii, or A. sachalinensis for $\mathrm{FL}_{M}$; however, only logs of Picea species were selected for $\mathrm{FL}_{B}$ because seeds tended to fall off the smooth bark of $A$. sachalinensis logs before germination. Seeds of $P$. jezoensis were collected in autumn 1998 at Rukushi Pass, $62 \mathrm{~km}$ from the study plot $\left(43^{\circ} 57^{\prime} \mathrm{N}, 143^{\circ} 44^{\prime} \mathrm{E}\right.$; $238 \mathrm{~m}$ a.s.l.), and were stored at $4^{\circ} \mathrm{C}$ until they were sown 
onto all $\mathrm{FL}_{B}$ and $\mathrm{FL}_{M}$ in May 2002. The relative light intensity (RLI), calculated as the light intensity relative to an open site, was measured above $\mathrm{FL}_{B}$ and $\mathrm{FL}_{M}$ in August 2003 using an illuminometer (T-1H, Konica Minolta Holdings, Inc., Tokyo, Japan); RLI was $16.1 \pm 5.5 \%$ for $\mathrm{FL}_{B}$ and $10.7 \pm 3.2 \%$ for $\mathrm{FL}_{M}$ (average $\pm \mathrm{SD}$ ). Germination ratios on $\mathrm{FL}_{B}$ and $\mathrm{FL}_{M}$ in 2002 were $6.5 \pm 5.8 \%$ and $8.5 \pm 7.5 \%$ (average $\pm \mathrm{SD}$ ), respectively.

We measured trends in $\Psi_{H}$ and $\Psi_{N}$ by drying the logs in a temperature-controlled greenhouse because the forest frequently experienced night dew. Experiments in the greenhouse were conducted from mid-June to early October 2003 at the Hokkaido research center of FFPRI. $\mathrm{FL}_{B}$ and $\mathrm{FL}_{M}$ were sampled from a coniferous forest at Mitsumata, Taisetsuzan National Park ( $43^{\circ} 31^{\prime} \mathrm{N}, 143^{\circ} 10^{\prime} \mathrm{E} ; 700 \mathrm{~m}$ a.s.l.) on 12 June 2003 because we could not sample fallen logs from the study plot at Sou-unkyo. The stand structure and species composition at Mitsumata was similar to that at Sou-unkyo. The sample logs were brought to the greenhouse on 13 June. Seeds of $P$. jezoensis were scattered on these logs on 22 July 2003, and the logs were irrigated daily. Germination was completed by mid-August. The fallen logs were shaded by black netting to prevent rapid desiccation. The greenhouse temperature was maintained at $23{ }^{\circ} \mathrm{C}$ during the day (7:00-19:00) and $15{ }^{\circ} \mathrm{C}$ at night $(19: 00-$ 7:00). The relative humidity fluctuated from $48 \%$ to $99 \%$. The mean VpdA was $0.34 \mathrm{kPa}$ during the experiments, which was higher than that at Sou-unkyo during the measurement of $\Psi_{H}$ and $\Psi_{N}$. The greenhouse was naturally lit, and the daily 
maximum photosynthetic photon flux density (PPFD) under the black netting was $266 \mu \mathrm{mol} \mathrm{m} \mathrm{m}^{-2} \mathrm{~s}^{-1}$.

The $\Psi_{N}$ and Fv/Fm of potted P. jezoensis seedlings were measured in the laboratory because sufficient shading of the seedlings to measure Fv/Fm in the greenhouse was difficult to achieve. We assumed that the ecophysiological conditions of the needles did not differ between seedlings on fallen logs and in pots. The seedlings were grown in an incubator (IN800, Yamato Scientific Co., Ltd., Tokyo, Japan), with the temperature maintained at $22{ }^{\circ} \mathrm{C}$ during the day $(5: 00-17: 00)$ and $15{ }^{\circ} \mathrm{C}$ at night (17:00-5:00). The relative humidity fluctuated from $20 \%$ to $90 \%$. The mean VpdA was $1.12 \mathrm{kPa}$ during the experiments. Light was supplied by a halogen lamp (JDR70, Ushiolighting, Inc., Hyogo, Japan), and the PPFD was $80 \mu \mathrm{mol} \mathrm{m}{ }^{-2} \mathrm{~s}^{-1}$ during the day. Seeds of $P$. jezoensis were scattered in six pots that were placed in the incubator on 3 March 2003. The basal area of the pots was $50.2 \mathrm{~cm}^{2}$, with a depth of $8 \mathrm{~cm}$, and the soil was a $3: 1(\mathrm{v} / \mathrm{v})$ mix of peat moss and vermiculite. We irrigated the seedlings every 2 days until the start of the experiments and supplied water-soluble nutrients every 2 weeks using a complete fertilizer (Hyponex 6-10-5, HYPONeX Japan, Corp., Ltd., Japan).

\section{Measurements}

In the natural forest, $\Psi_{H}$ was measured six times during the 2002 growing season and four times during the 2003 growing season. The predawn measurements were 
made using a thermocouple psychrometer (HR-33T \& C-52-SF, Wescor Inc., Logan, UT, USA) placed in a tent to avoid rapid temperature changes and direct radiation. One sample obtained from each fallen log was measured at each sampling. After excising the stem bark, a sample of the humus layer was collected using tweezers and immediately placed into the psychrometer chamber. The $\Psi_{N}$ of current-year and 1-year-old seedlings were measured in August 2002 and June 2003, respectively. June is typically the driest season in Hokkaido. Because seedlings in the plot began to germinate in July, the $\Psi_{N}$ of current-year seedlings was measured on 26 August 2002, shortly after a rainfall. The $\Psi_{N}$ of 1-year-old seedlings was measured on 15 June 2003, 11 days after a rainfall, and on 28 June 2003, shortly after a rainfall. Measurements were taken using a psychrometer in a tent at predawn and noon. Three or four seedlings were measured at each sampling. Only cotyledons were available for the measurement of $\Psi_{N}$ of current-year $P$. jezoensis seedlings. Oneyear-old needles that had expanded as cotyledons in the previous year were used for $\Psi_{N}$ measurements of 1-year-old seedlings because current-year needles had not yet expanded by June. Needles were detached from the seedlings using tweezers and immediately placed into the psychrometer chamber. Precipitation records were obtained from the nearest meteorological station at Sou-unkyo (Fig. 1).

In the greenhouse, seedlings were irrigated until 8 September 2003, 3 weeks after the last germination. Predawn measurements of $\Psi_{H}$ and $\Psi_{N}$ were taken at $0,8,10$, $16,17,21,23,29,31,36,38,44,49$, and 52 days after the cessation of irrigation. The 
methods and number of samples for $\Psi_{H}$ measurements were the same as those used in the forest. Cotyledons from three or four seedlings were used for $\Psi_{N}$ measurements. Cotyledon expansion was completed by the start of the experiments.

In the incubator, seedlings were irrigated until 27 April 2003, 4 weeks after the last germination. The $\Psi_{N}$ and Fv/Fm of the seedlings were measured before the incubator was illuminated at 1, 9, 12, 15, 23, 27, 30, 34, 41, and 42 days after the cessation of irrigation. Nine seedlings from six pots were randomly sampled and measured. The measurements of Fv/Fm were conducted using a chlorophyll fluorometer (MINI-PAM, Heinz Walz GmbH, Effeltrich, Germany) in a darkroom with shading. Cotyledon expansion was completed when the measurements started. The $\Psi_{N}$ was measured after $\mathrm{Fv} / \mathrm{Fm}$, and the gravimetric water content of soil samples from the bottom of the pots was measured to monitor the water status of the soil. Soils were weighed before and after drying at $70{ }^{\circ} \mathrm{C}$ for 3 days.

The possibility of critical droughts occurring at Sou-unkyo was estimated based on meteorological data and the results of the experiments described above. We searched the data recorded by the nearest meteorological station at Sou-unkyo from 1994 to 2003 to identify periods with no precipitation that lasted longer than 11 days, which was the longest precipitation-free period during our $\Psi_{N}$ measurements in the forest. 


\section{Statistical analysis}

The effects of the presence of moss and the lack of precipitation on the $\Psi_{N}$ of 1-yearold seedlings at predawn and noon in the forest were analyzed using two-way analysis of variance (ANOVA). Statistical analysis was performed using R ( R Development Core Team 2004). The significance level was $5 \%$.

\section{Results}

The mean $\Psi_{H}$ in the natural forest was about $0 \mathrm{MPa}$, regardless of the presence of moss or the length of time without precipitation (Fig. 1). The predawn VpdA during $\Psi_{N}$ measurements was $0.01 \mathrm{kPa}$ both shortly after and 11 days after precipitation. The mean predawn $\Psi_{N}$ of 1-year-old seedlings on $\mathrm{FL}_{B}$ and $\mathrm{FL}_{M}$ measured soon after precipitation was $-0.3 \mathrm{MPa}\left(\mathrm{n}=1\right.$ for $\mathrm{FL}_{B}$ because of measurement errors in this experiment) and -0.7 MPa, respectively (Fig. 2). The $\Psi_{N}$ of 1-year-old seedlings on $\mathrm{FL}_{B}$ and $\mathrm{FL}_{M}$ measured 11 days after a rainfall was -0.8 and $-0.7 \mathrm{MPa}$, respectively. Neither the presence of moss, nor the length of time without precipitation, had a significant effect on the mean predawn $\Psi_{N}$ (Table 2, $p>0.05$ ). The noon VpdA during $\Psi_{N}$ measurements was $0.8 \mathrm{kPa}$ shortly after a rainfall and $1.0 \mathrm{kPa} 11$ days after precipitation. Shortly after precipitation, the mean noon $\Psi_{N}$ of 1-year-old seedlings on $\mathrm{FL}_{B}$ and $\mathrm{FL}_{M}$ was -1.1 and $-1.0 \mathrm{MPa}$ (Fig. 2) and -1.4 and -1.0 MPa 11 days after precipitation, respectively. The mean noon $\Psi_{N}$ was significantly 
affected by the presence of moss (Table $2, p<0.01$ ). Shortly after precipitation, the mean $\Psi_{N}$ of current-year seedlings on $\mathrm{FL}_{B}$ and $\mathrm{FL}_{M}$ was -0.8 and $-0.6 \mathrm{MPa}$ at predawn and -1.2 and -1.0 MPa at noon, respectively. There was little difference in the mean predawn $\Psi_{N}$ between current-year and 1-year-old seedlings (Fig. 2; data for current-year seedlings not shown).

The $\Psi_{H}$ of $\mathrm{FL}_{B}$ in the greenhouse remained at $0 \mathrm{MPa}$ until 17 days after irrigation ceased and then decreased rapidly (Fig. 3). The mean $\Psi_{N}$ on $\mathrm{FL}_{B}$ sharply decreased to less than -3.0 MPa between days 31 and 36 . The $\Psi_{H}$ of $\mathrm{FL}_{M}$ in the greenhouse also remained at $0 \mathrm{MPa}$ until 29 days after the cessation of irrigation, decreased slightly, and then rapidly decreased on day 49 . The mean $\Psi_{N}$ on the $\mathrm{FL}_{M}$ gradually decreased from -1.4 to -2.5 MPa between days 31 and 49, and further rapidly decreased on day 52. Thus, the decrease in the mean $\Psi_{N}$ followed that of $\Psi_{H}$.

The mean gravimetric soil water content of pots in the incubator decreased gradually after irrigation ceased and leveled off after 15 days (Fig. 4). The mean $\Psi_{N}$ of potted seedlings decreased rapidly from -1.0 to $-6.0 \mathrm{MPa}$ on day 41 . The mean Fv/Fm also decreased rapidly from 0.8 to $<0.4$ on day 41 . Many of the potted seedlings began to die on day 41 . Figure 5 shows the relationship between $\Psi_{N}$ and Fv/Fm, which decreased significantly when $\Psi_{N}$ was less than -2.6 MPa.

Periods with no precipitation that lasted longer than 11 days were recorded only four times at Sou-unkyo between 1994 and 2003. The lengths of each precipitationfree period were 16 days (2003), 18 days (2001), 12 days (1998), and 12 days (1994). 


\section{Discussion}

Although the $\Psi_{H}$ of $\mathrm{FL}_{B}$ was approximately equal to that of $\mathrm{FL}_{M}$ shortly after irrigation ceased in the greenhouse, it subsequently decreased faster than that of

$\mathrm{FL}_{M}$ (Fig. 3). Consequently, $\mathrm{FL}_{B}$ tended to dry more rapidly than $\mathrm{FL}_{M}$. There are two possible explanations for the slow reduction of $\Psi_{H}$ on $\mathrm{FL}_{M}$ : the thick humus layer of $\mathrm{FL}_{M}$ contains a lot of water and the moss reduces the rate of evaporation. In previous studies, single measurements of stem water content have shown that freshly fallen, bare logs are drier than decayed, moss-covered logs (Yoneda 1975; McKenny and Kirkpatrick 1999; Takahashi et al. 2000; Wiklund 2003), which supports our results. The decrease in $\Psi_{H}$ resulted in a decrease in the mean $\Psi_{N}$ (Fig. 3). Thus, under dry conditions, seedlings on $\mathrm{FL}_{B}$ suffered from drought stress earlier than those on $\mathrm{FL}_{M}$.

How critical is drought stress for current-year and 1-year-old seedlings of $P$. jezoensis? In the experiments with potted seedlings, current-year seedlings began to die 41 days after irrigation ceased and the mean $\Psi_{N}$ concurrently dropped from -1.0 to $-6.0 \mathrm{MPa}$ (Fig. 4). The Fv/Fm ratio decreased to $<0.6$ when $\Psi_{N}$ was $<-2.6$ $\mathrm{MPa}$ (Fig. 5). The Fv/Fm ratio of healthy plants is usually $0.8-0.83$, independent of species (Björkman and Demming 1987), and is highly drought-tolerant (Genty et al. 1986; Di-Marco et al. 1988; Epron and Dreyer 1992; Ann et al. 1995; Lu and Zhang 1998; Augusti et al. 2001). For example, Ann et al. (1995) showed that the 
Fv/Fm ratio of potted seedlings of Picea glauca (Moench) Voss $\times$ P. engelmanni Parry was maintained at 0.8 , even when the needle water potential decreased to -2.3 MPa, which is the turgor-loss point for this hybrid. Epron and Dreyer (1992) showed that the Fv/Fm ratio of leaf disks of Quercus petraea decreased below 0.8 after the cell membranes broke because of desiccation. Therefore, the Fv/Fm ratio probably does not decrease until immediately before needle mortality caused by drought. Our results suggest that the critical $\Psi_{N}$ of current-year $P$. jezoensis seedlings is -2.6 MPa because the Fv/Fm ratio apparently decreased to $<0.8$ when this $\Psi_{N}$ was reached. The critical $\Psi_{N}$ indicated by the $\mathrm{Fv} / \mathrm{Fm}$ ratio may be underestimated as the maximum recoverable value of $\Psi_{N}$ because turgor loss or cell membrane breakage probably occurred before the decrease in Fv/Fm. The critical $\Psi_{N}$ for plant mortality due to drought stress in coniferous seedlings is $-2.5 \mathrm{MPa}$ for Picea mariana (Black and Bliss 1980) and -2.1 MPa for Pinus nigra ssp. laricio var. Corsicana (Guehl et al. 1993); these $\Psi_{N}$ values are not significantly different from the -2.6 MPa obtained in our pot experiments. Because the mean $\Psi_{N}$ of currentyear and 1-year-old seedlings shortly after precipitation in the forest was similar at predawn and noon, the critical $\Psi_{N}$ value of -2.6 MPa obtained for current-year seedlings may also be applicable to 1-year-old seedlings.

Assuming that the critical $\Psi_{N}$ for $P$. jezoensis is $-2.6 \mathrm{MPa}$, the lengths of the precipitation-free periods that cause critical drought stress for seedlings were estimated to be 36 days for $\mathrm{FL}_{B}$ and 56 days for $\mathrm{FL}_{M}$ in the greenhouse. These values 
are prpbably applicable to the forest because the mean $\mathrm{VpdA}$ of the greenhouse $(0.34 \mathrm{kPa})$ did not differ significantly from that of the forest $(0.28 \mathrm{kPa})$.

One-year-old seedlings in the forest did not experience critical drought stress. At 11 days after the last precipitation event, which was the longest period without precipitation during our $\Psi_{N}$ measurements in the forest, the mean $\Psi_{H}$ was $0 \mathrm{MPa}$ regardless of the presence of moss (Fig. 1). At the same time, the mean predawn $\Psi_{N}$ on $\mathrm{FL}_{B}$ and $\mathrm{FL}_{M}$ was -0.8 and $-0.7 \mathrm{MPa}$, respectively, and the mean noon $\Psi_{N}$ was -1.4 and -1.0 MPa, respectively (Fig. 2). Therefore, 11 days after precipitation, neither moss-covered nor bare logs were dry, and seedlings growing on them did not suffer intense drought stress. The presence of moss on the fallen logs affected the water status of the seedlings only at noon (Table 2). Although precipitationfree periods in excess of 11 days were recorded four times between 1994 and 2003, critical drought events (no precipitation for $>36$ days) never occurred in the forest in those 10 years. Moreover, the relative humidity was near $100 \%$ at night, even during the dry period. Night dew occurred frequently in the forest (Iijima, personal observation), which mitigates the drought stress of the seedlings (Boucher et al. 1995). Accordingly, drought stress may not cause seedling mortality on $\mathrm{FL}_{B}$, which dry faster than $\mathrm{FL}_{M}$, in this forest.

In conclusion, fallen logs without mosses tend to dry more quickly than mosscovered logs, but a fairly long drought would be necessary for either type of log to dry completely. Furthermore, critical drought stress for seedlings occurs after the 
humus layer of fallen logs has desiccated. Consequently, the presence of moss does not affect the survival of current- and 1-year-old P. jezoensis seedlings on fallen logs by affecting the water status of the logs. However, further study is needed to examine the drought hypothesis using larger seedlings because small seedlings use a smaller amount of water, which may mask differences in water status between $\mathrm{FL}_{B}$ and $\mathrm{FL}_{M}$. The causes of the variation in seedling density on logs will be further clarified by considering differences in seed retention (Harmon 1988), germination, survival and growth (Iijima et al. 2004) between $\mathrm{FL}_{B}$ and $\mathrm{FL}_{M}$.

\section{Acknowledgements}

The authors thank the members of the forest dynamics and diversity group at the Hokkaido research center of FFPRI for permission to conduct research in their plot, and members of the soil-plant ecosystem group at the research center for their maintaining the greenhouse and allowing us to use it. We also thank to Ms. Sato of the laboratory of silviculture, Hokkaido University, for irrigating the fallen logs in the greenhouse, and students in the laboratory of silviculture and forest resource biology, Hokkaido University, for assistance with field work. 


\section{References}

Ann, P., Eastman, K., and Camm, E.L. 1995. Regulation of photosynthesis in interior spruce during water stress: changes in gas exchange and chlorophyll fluorescence. Tree Physiol. 15: 229-235.

Augusti, A., Scartazza, A., Navari-Izzo, F., Sgherri, C.L.M., Stevanovic, B., and Brugnoli, E. 2001. Photosystem II photochemical efficiency, zeaxanthin and antioxidant contents in the poikilogydric Ramonda serbica during dehydration and rehydration. Photosynth. Res. 67: 79-88. doi: 10.1023/A:1010657000548.

Björkman, O., and Demming, B. 1987. Photon yield of $\mathrm{O}_{2}$ evolution and chlorophyll fluorescence characteristics at $77 \mathrm{~K}$ among vascular plants of diverse origin. Planta, 170: 489-504.

Black, R.A., and Bliss, L.C. 1980. Reproductive ecology of Picea mariana (Mill.) BSP., at tree line near Inuvik, northern territories, Canada. Ecol. Monogr. 50: 331-354.

Boucher, J.-F., Munson, A.D., and Bernier, P.Y. 1995. Foliar absorption of dew influences shoot water potential and root growth in Pinus strobus seedlings. Tree Physiol. 15: 819-823.

Cavender, J., and Bazzaz, F.A. 2000. Changes in drought responses strategies with ontogeny in Quercus rubra: implications for scaling from seedlings to mature trees. Oecologia, 124: 8-18.

Cheng, D., and Igarashi, T. 1985. Basic study of the regeneration of Picea jezoensis -survival of current-year seedlings on various forest floors during growth period[In Japanese]. Proc. 96th Jpn. For. Sci. Meet. 96: 377-378.

Cheng, D., and Igarashi, T. 1986. Fungi associated with natural regeneration of Picea jezoensis CARR. in seedlings stage (I) -Fungi detected from over wintered seeds on various forest floors- [In Japanese]. Proc. 97th Jpn. For. Sci. Meet. 97: 495-496.

Cheng, D., and Igarashi, T. 1987. Fungi associated with natural regeneration of Picea jezoensis CARR. in seed stage - Their distribution on forest floors and pathogenicity to the seeds-. Res. Bull. Coll. Exp. For. Fac. Agric. Hokkaido Univ. 44: 175-188.

Christy, E.J., and Mack, R.N. 1984. Variation in demography of juvenile Tsuga heterophylla across the substratum mosaic. J. Ecol. 72: 75-91.

Di-Marco, G., Massacci, A., and Gabrielli, R. 1988. Drought effects on photosynthesis and fluorescence in hard wheat cultivars grown in the field. Physiol. Plant. 74: $385-390$.

Donovan, L.A., and Ehleringer, J.R. 1991. Ecophysiological differences among juvenile and reproductive plants of several woody species. Oecologia, 86: 594-597. 
Donovan, L.A., and Ehleringer, J.R. 1992. Contrasting water-use patterns among size and life-history classes of a semi-arid shrub. Funct. Ecol. 6: 482-488.

Epron, D., and Dreyer, E. 1992. Effects of severe dehydration on leaf photosynthesis in Quercus petraea (Matt.) Liebl.: photosystem II efficiency, photochemical and nonphotochemical fluorescence quenching and electrolyte leakage. Tree Physiol. 10: 273-284.

Genty, B., Briantais, J.-M., and Silva, J.B.V.D. 1986. Effects of drought on primary photosynthetic processes of cotton leaves. Plant Physiol. 83: 360-364.

Guehl, J.M., Clement, A., Kaushal, P., and Aussenac, G. 1993. Planting stress, water status and non-structural carbohydrate concentrations in Corsican pine seedlings. Tree Physiol. 12: 173-183.

Harmon, M.E. 1987. The influence of litter and humus accumulations and canopy openness on Picea sitchensis (Bong.) and Tsuga heterophylla (Raf.) Sarg. seedlings growing on logs. Can. J. For. Res, 17: 1475-1479.

Harmon, M.E. 1988. Retention of needles and seeds on logs in Picea sitchensis Tsuga heterophylla forests of coastal Oregon and Washington. Can. J. Bot. 67: 1833-1837.

Harmon, M.E., and Franklin, J.F. 1989. Tree seedlings on logs in Picea-Tsuga forests of Oregon and Washington. Ecology, 70: 48-59.

Hiura, T., Sano, J., and Konno, Y. 1996. Age structure and response to fine-scale disturbances of Abies sachalinensis, Picea jezoensis, Picea glehnii, and Betula ermanii growing under the influence of a dwarf bamboo understory in northern Japan. Can. J. For. Res. 26: 289-297.

Iijima, H., Shibuya, M., Saito, H., and Takahashi, K. 2004. The effect of moss height on survival and growth of Picea jezoensis seedlings on fallen logs [In Japanese with English summary]. Jpn. J. For. Res. 86: 358-364.

Kubota, Y., Konno, Y., and Hiura, T. 1994. Stand structure and growth patterns of understorey trees in a coniferous forest, Taisetsuzan National Park, northern Japan. Ecol. Res. 9: 333-341.

Larcher, W. 1995. Physiological Plant Ecology. 3rd ed. Springer, Berlin.

Lu C., and Zhang, J. 1998. Effects of water stress on photosynthesis, chlorophyll fluorescence and photoinhibition in wheat plants. Aust. J. Plant Physiol. 25: 883892.

Maruyama, R., Maruyama, M., and Konno, Y. 2004. Effects of understory vegetation and litter on the establishment of Abies sachalinensis and Picea jezoensis seedlings in a conifer forest in Hokkaido, northern Japan [In Japanese with English summary]. Jpn. J. Ecol. 54: 105-116. 
McCullough, H.A. 1948. Plant succession on fallen logs in a virgin spruce-fir forest. Ecology, 29: 508-513.

McKenny, H.J.A., and Kirkpatrick, J.B. 1999. The role of fallen logs in the regeneration of tree species in Tasmanian mixed forest. Aust. J. Bot. 47: 745-753.

Mori, A., Mizumachi, E., Osono, T., and Doi, Y. 2004. Substrate-associated seedling recruitment and establishment of major conifer species in an old-growth subalpine forest in central Japan. For. Ecol. Manag. 196: 287-297.

Nakagawa, M., Kurahashi, A., Kaji, M., and Hogetsu, T. 2001. The effects of selection cutting on regeneration of Picea jezoensis and Abies sachalinensis in the sub-boreal forests of Hokkaido, northern Japan. For. Ecol. Manag. 146: 15-23. doi: 10.1016/s0378-1127(00)00445-x.

Nakamura, T. 1992. Effect of bryophytes on survival of conifer seedlings in subalpine forests of central Japan. Ecol. Res. 7: 155-162.

Narukawa, Y., Iida, S., Tanouchi, H., Abe, S., and Yamamoto, S. 2003. State of fallen logs and the occurrence of conifer seedlings and saplings in boreal and subalpine old-growth forests in Japan. Ecol. Res. 18: 267-277. doi: 10.1046/j.14401703.2003/00553.x

Natsume, S. 1985. Studies on the habitat conditions and early growth in the natural regeneration of Picea jezoensis Carr. [In Japanese with English summary]. Res. Bull. Coll. Exp. For. Fac. Agric. Hokkaido Univ. 42: 47-107.

R Development Core Team. 2004. R: a language and environment for statistical computing. R Foundation for Statistical Computing, Vienna, Austria. ISBN 3900051-07-0, URL http://www.R-project.org.

Simard, M.J., Bergeron, Y., and Sirois, L. 1998. Conifer seedling recruitment in a south-eastern Canadian boreal forest: the importance of substrate. J. Veg. Sci. 9: $575-582$.

Suzuki, E., Ota, K., Igarashi, T., and Fujiwara, K. 1987. Regeneration process of coniferous forests in northern Hokkaido I. Abies sachalinensis forest and Picea glehnii forest. Ecol. Res. 2: 61-75.

Szewczyk, J., and Szwagrzyk J. 1996. Tree regeneration of rotten wood and on soil in old-growth stand. Vegetatio, 122: 37-46.

Takada, K., Shibata, Z., and Sato, S. 1973. Study of the natural regeneration of Picea jezoensis and Abies sachalinensis (I) -Emergence and disappearance of seedlings on fallen logs and cut stumps- [In Japanese]. Trans. Meet. Hokkaido Branch Jpn. For. Soc. Sapporo, 22: 45-48. 
Takahashi, I. 1991. Studies on the mycofloral succession on Yezo spruce (Picea jezoensis CARR.) in various stages of growth, with special reference to the role of Fungi in the natural regeneration of the Host [In Japanese with English summary]. Res. Bull. Coll. Exp. For. Fac. Agric. Tokyo Univ. 86: 201-273.

Takahashi, K. 1994. Effect of size structure, forest floor type and disturbance regime on tree species composition in a coniferous forest in Japan. J. Ecol. 82: 769-773.

Takahashi, M., Sakai, Y., Ootomo, R., and Shinozaki, M. 2000. Establishment of tree seedlings and water-soluble nutrients in coarse woody debris in an old-growth Picea-Abies forest in Hokkaido, northern Japan. Can. J. For. Res. 30: 1148-1155.

Tamate, S., Kashiyama, T., Sasanuma, T., Takahashi, K., and Matsuoka, H. 1977. On the distribution maps of forest wind damaged by Typhoon No. 15, 1954 in Hokkaido [In Japanese]. Bull. Gov. For. Exp. Stn. Tokyo, 289: 43-67.

Taylor, A.H. 1990. Disturbance and persistence of sitka spruce (Picea sitchensis (Bong) Carr.) in coastal forests of the pacific northwest, North America. J. Biogeogr. 17: 47-58.

Wiklund, K. 2003. Phosphorus concentration and pH in decaying wood affect establishment of the red-listed moss Buxbaumia viridis. Can. J. Bot. 81: 541-549. doi: 10.1139/B03-048.

Yoneda, T. 1975. Studies on the rate of decay of wood litter on the forest floor I. Some physical properties of decaying wood. Jpn. J. Ecol. 25: 40-46. 
Table 1: Stand condition. BA, basal area; DBH, diameter at breast height; ${ }^{*}$ Trees in $\mathrm{DBH} \geq 5 \mathrm{~cm}$.

\begin{tabular}{lrr}
\hline Species & Density $\left(\text { trees ha }{ }^{-1}\right)^{*}$ & $\mathrm{BA}_{\left(\mathrm{m}^{2} \mathrm{ha}^{-1}\right)}$ \\
\hline Picea glehnii & $206(31.2 \%)$ & $14.8(43.4 \%)$ \\
Picea jezoensis & $94(14.6 \%)$ & $23.3(28.9 \%)$ \\
Abies sachalinensis & $332(51.7 \%)$ & $15.6(27.5 \%)$ \\
Broadleaf & $10(1.6 \%)$ & $0.1(0.1 \%)$ \\
\hline
\end{tabular}


Table 2: The effect of and the presence of moss and the lack of precipitation on the $\Psi_{N}$ of 1-year-old seedlings at predawn and noon analyzed using two-way analysis of variance. The presence of moss indicates logs without and with moss (i.e., $\mathrm{FL}_{B}$ and $\left.\mathrm{FL}_{M}\right)$.

\begin{tabular}{llrrrrr}
\hline Time & Factors & SS & d.f. & MS & $F$-value & $p$ \\
\hline \multirow{2}{*}{ Predawn } & Lack of precipitation & 0.16 & 1 & 0.16 & 1.92 & 0.203 \\
& Presence of moss & 0.03 & 1 & 0.03 & 0.31 & 0.595 \\
& Lack of precipitation $\times$ Presence of moss & 0.10 & 1 & 0.10 & 1.19 & 0.308 \\
& Residual & 0.67 & 8 & 0.80 & & \\
\hline \multirow{2}{*}{ Noon } & Lack of precipitation & 0.03 & 1 & 0.03 & 1.64 & 0.229 \\
& Presence of moss & 0.22 & 1 & 0.22 & 11.43 & 0.007 \\
& Lack of precipitation $\times$ Presence of moss & 0.08 & 1 & 0.08 & 4.22 & 0.067 \\
& Residual & 0.19 & 10 & 0.02 & & \\
\hline
\end{tabular}




\section{Captures}

Figure 1. Seasonal changes in precipitation and $\Psi_{H}$. (a) 2002, (b) 2003. $\Psi_{H}$ : predawn water potential of the humus layer on a fallen log; ○: $\Psi_{H}$ on $\mathrm{FL}_{B} ; \times: \Psi_{H}$ on $\mathrm{FL}_{M}$; solid lines indicate precipitation.

Figure 2. Mean $\Psi_{N}$ of 1-year-old needles with varying duration of no precipitation. $\Psi_{N}$ : water potential of 1-year-old needles; dotted bars indicate predawn $\Psi_{N}$, open bars indicate noon $\Psi_{N}$, error bars indicate SD ( $\mathrm{n}=3-4$ seedlings).

Figure 3. Changes in predawn $\Psi_{H}$ and $\Psi_{N}$ after the cessation of irrigation. (a) $\mathrm{FL}_{B}$, (b) $\mathrm{FL}_{M} . \square: \Psi_{H} ; \circ$ : $\Psi_{N}$; error bars indicate $\mathrm{SD}(\mathrm{n}=3-4$ seedlings).

Figure 4. Changes in predawn $\Psi_{N}, \mathrm{Fv} / \mathrm{Fm}$ and gravimetric soil water content after the cessation of irrigation. (a) Relationship between $\Psi_{N}$ and gravimetric soil water content. $\square$ : gravimetric soil water content; $\circ$ : $\Psi_{N}$. (b) Relationship between Fv/Fm and gravimetric soil water content. $\square$ : gravimetric soil water content; $\circ$ : Fv/Fm. Error bars indicate SD in both graphs ( $\mathrm{n}=8-9$ seedlings $)$.

Figure 5. Relationship between predawn $\Psi_{N}$ and Fv/Fm. The vertical line indicate $\Psi_{N}=-2.6 \mathrm{MPa}$. 


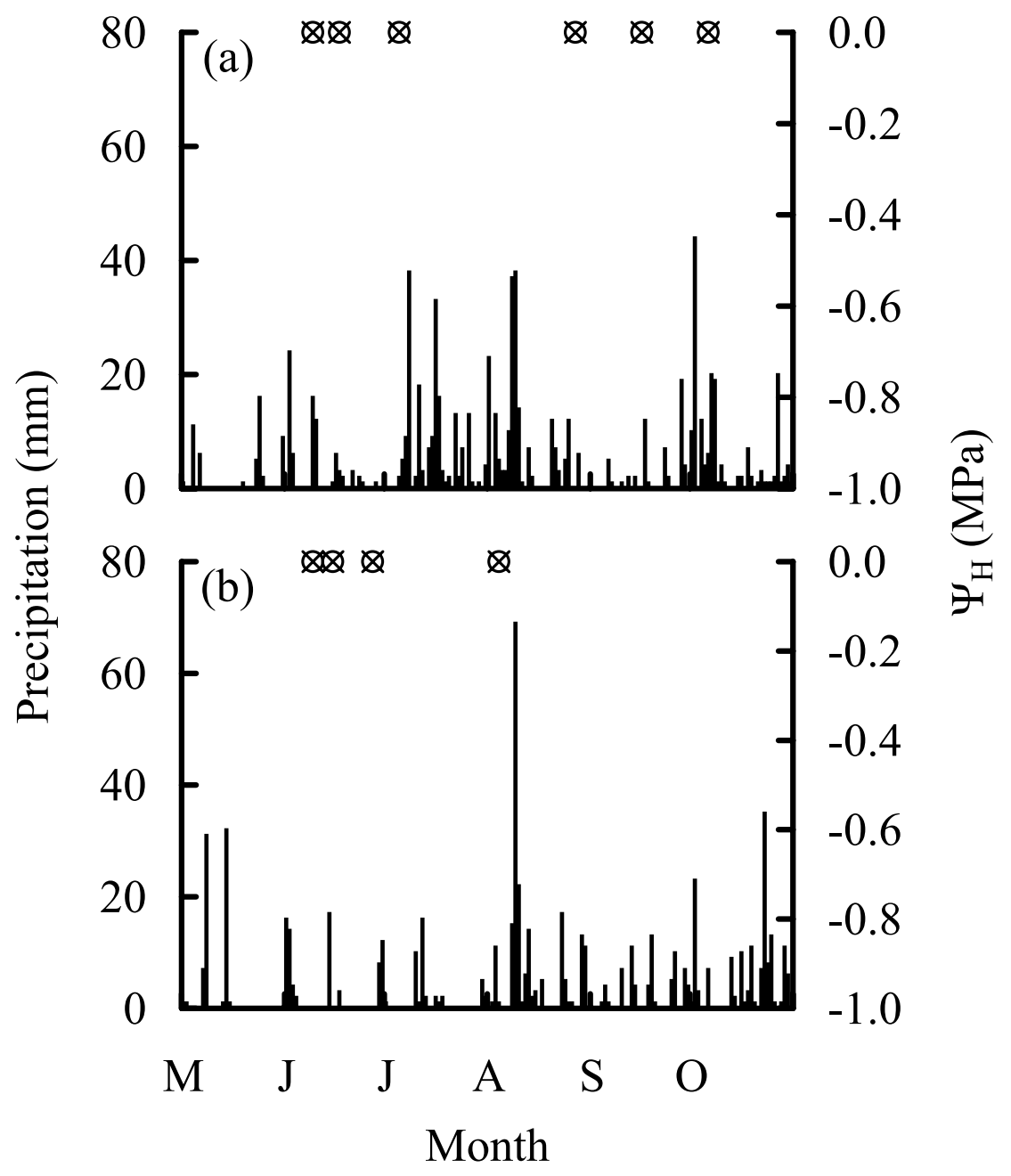

Figure 1: 


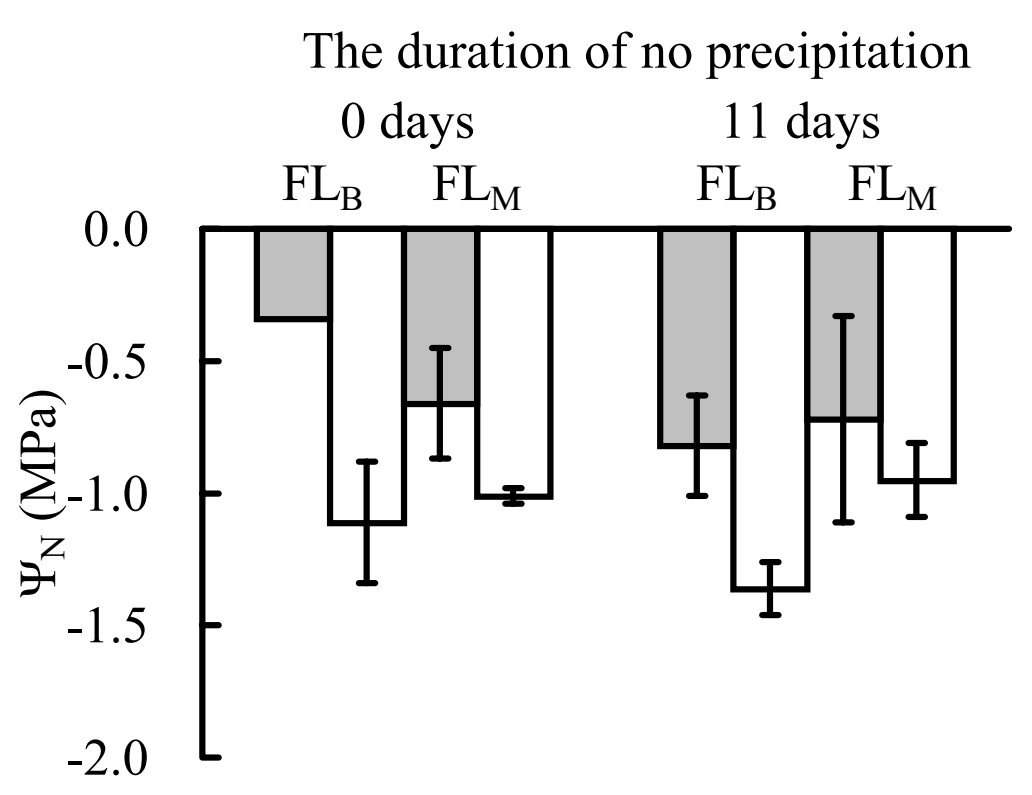

Figure 2: 


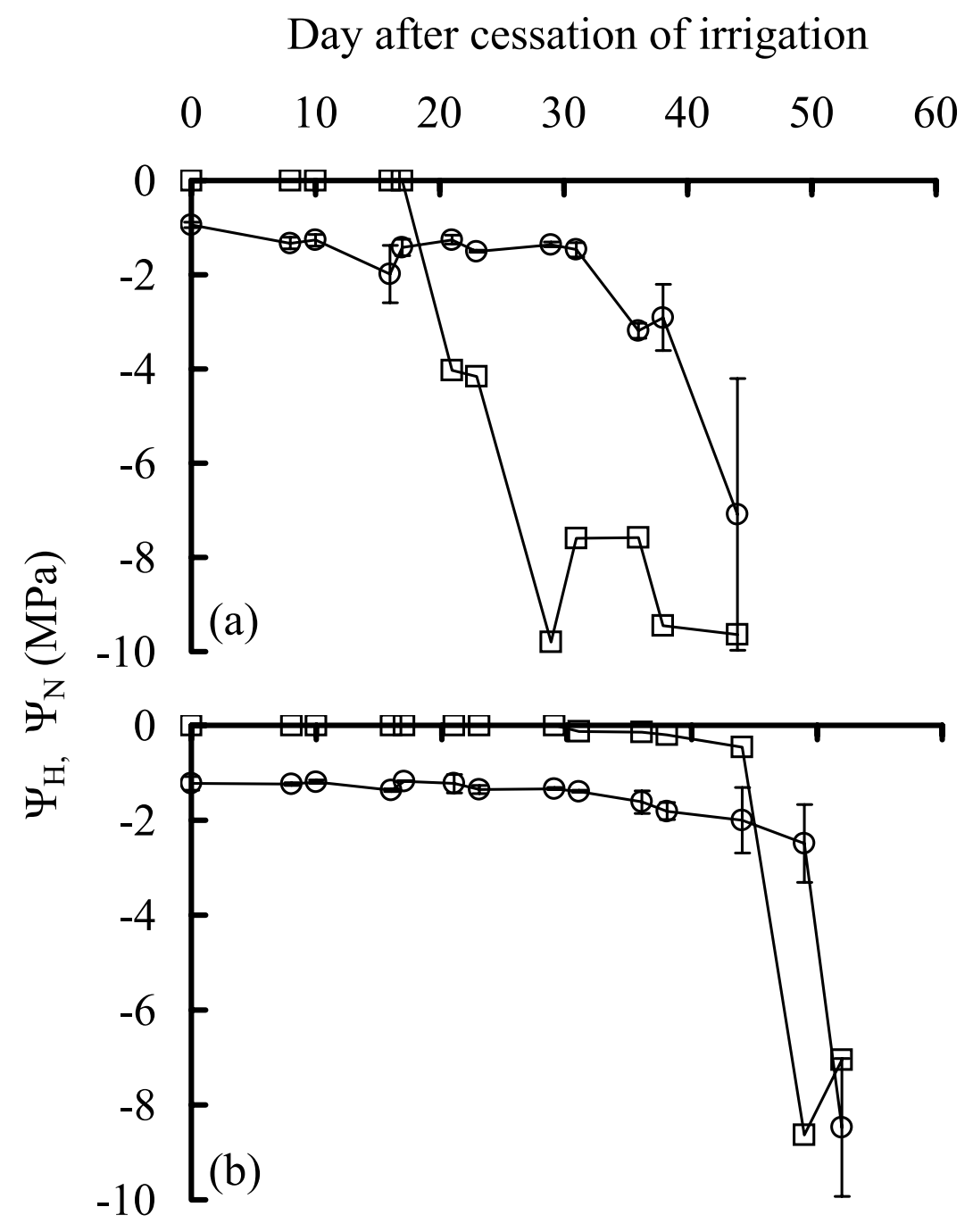

Figure 3: 


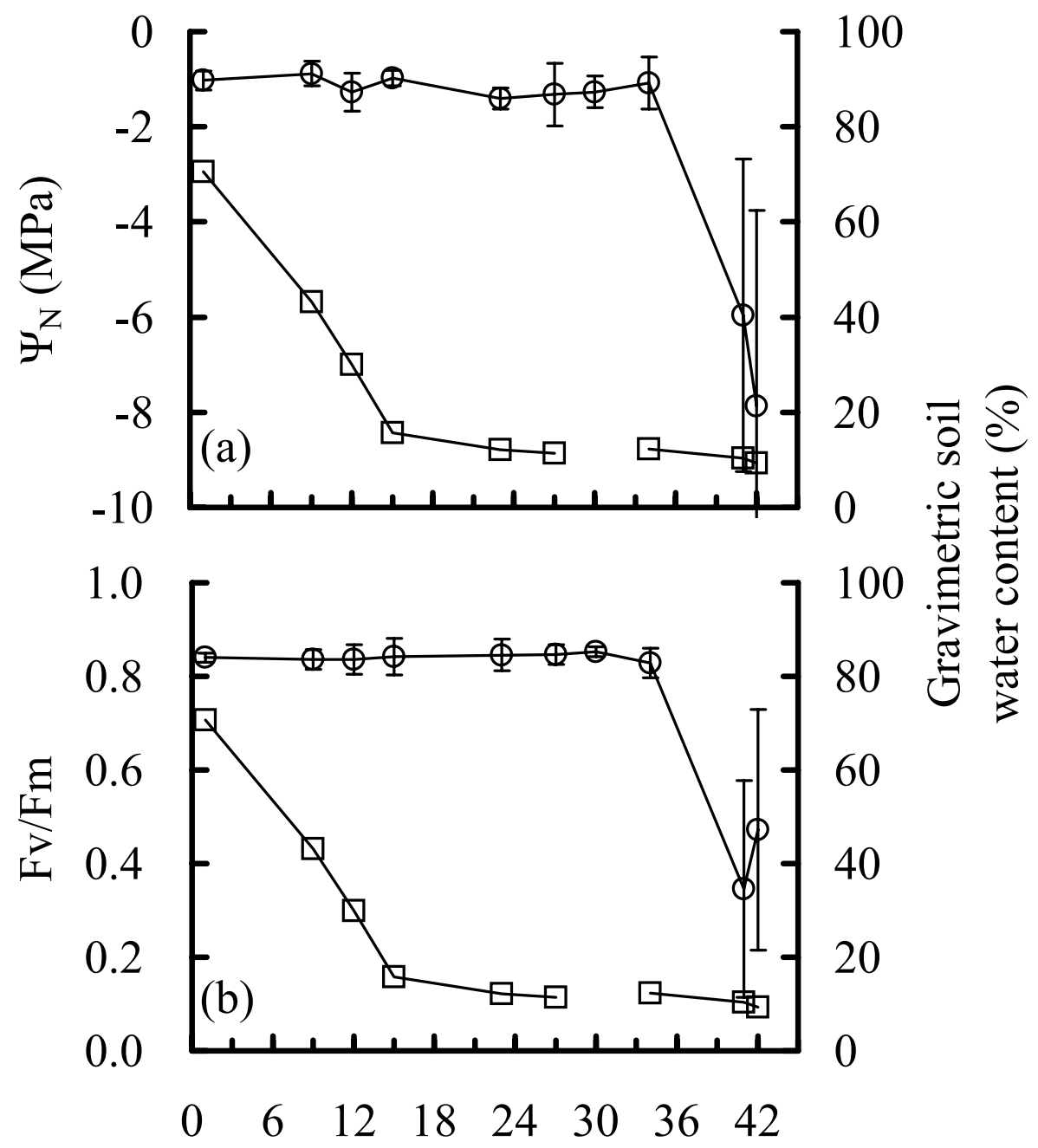

Day after cessation of irrigation

Figure 4: 


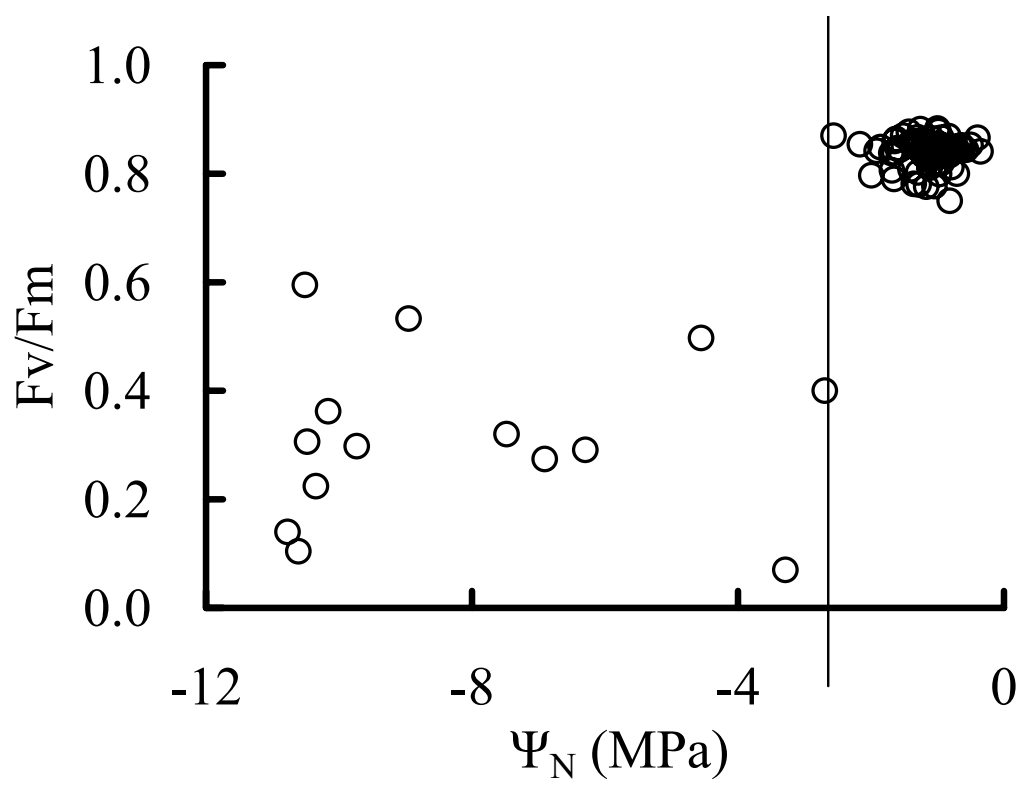

Figure 5: 